\title{
Correction to: Gender differences and determinants of prevalence, awareness, treatment and control of hypertension among adults in China and Sweden
}

Ailiana Santosa ${ }^{1,2+}$, Yue Zhang ${ }^{3 \dagger}$, Lars Weinehall ${ }^{1}$, Genming Zhao ${ }^{3}$, Na Wang ${ }^{3}$, Qi Zhao ${ }^{3}$, Weibing Wang ${ }^{3 *}$ and Nawi $\mathrm{Ng}^{1,2^{*}}$

\section{Correction to: BMC Public Health 20, 1763 (2020)}

\section{https://doi.org/10.1186/s12889-020-09862-4}

It was highlighted that the original article [1] contained the wrong Figs. 1, 2, 3 and 4. This Correction article shows the correct Figs. 1, 2, 3 and 4. The original article has been updated.

\section{Author details}

'Department of Epidemiology and Global Health, Faculty of Medicine, Umeå University, 90187 Umeå, Sweden. ${ }^{2}$ Global Public Health, School of Public Health and Community Medicine, Institution of Medicine, Sahlgrenska Academy, University of Gothenburg, 41390 Gothenburg, Sweden. ${ }^{3}$ School of Public Health, Key Laboratory of Public Health Safety of Ministry of Education, Fudan University, Shanghai 200032, China.

Published online: 04 January 2021

\section{Reference}

1. Santosa A, et al. Gender differences and determinants of prevalence, awareness, treatment and control of hypertension among adults in China and Sweden. BMC Public Health. 2020;20:1763. https://doi.org/10.1186/ s12889-020-09862-4.

\footnotetext{
The original article can be found online at https://doi.org/10.1186/s12889020-09862-4.

*Correspondence: wwb@fudan.edu.cn; nawi.ng@umu.se; nawi.ng@gu.se

${ }^{\dagger}$ Ailiana Santosa and Yue Zhang contributed equally to this work.

${ }^{3}$ School of Public Health, Key Laboratory of Public Health Safety of Ministry of Education, Fudan University, Shanghai 200032, China

'Department of Epidemiology and Global Health, Faculty of Medicine, Umeå University, 90187 Umeå, Sweden

Full list of author information is available at the end of the article
}

(c) The Author(s). 2020 Open Access This article is licensed under a Creative Commons Attribution 4.0 International License, which permits use, sharing, adaptation, distribution and reproduction in any medium or format, as long as you give appropriate credit to the original author(s) and the source, provide a link to the Creative Commons licence, and indicate if changes were made. The images or other third party material in this article are included in the article's Creative Commons licence, unless indicated otherwise in a credit line to the material. If material is not included in the article's Creative Commons licence and your intended use is not permitted by statutory regulation or exceeds the permitted use, you will need to obtain permission directly from the copyright holder. To view a copy of this licence, visit http://creativecommons.org/licenses/by/4.0/ The Creative Commons Public Domain Dedication waiver (http://creativecommons.org/publicdomain/zero/1.0/) applies to the data made available in this article, unless otherwise stated in a credit line to the data. 


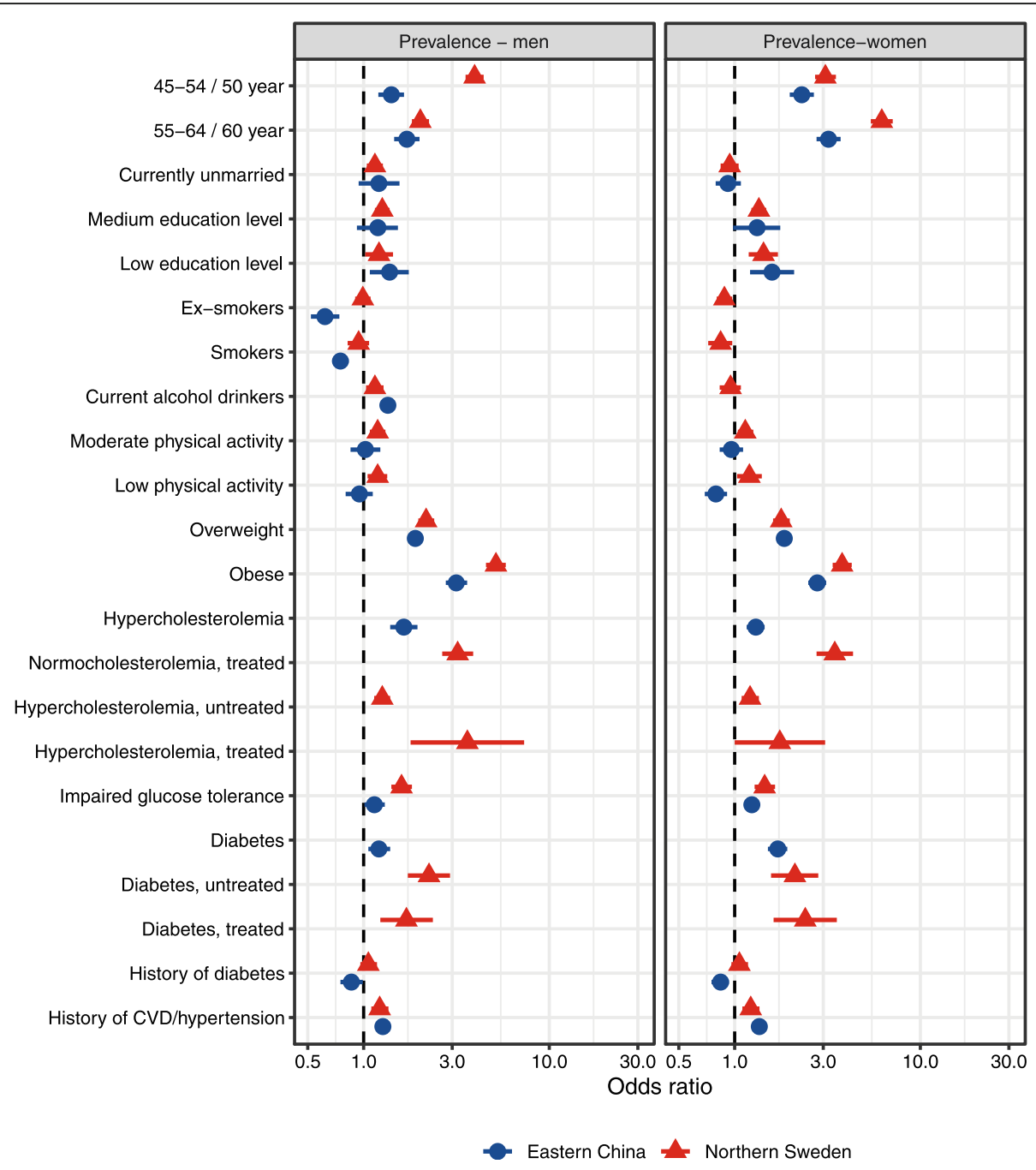

Fig. 1 The determinants of prevalence of hypertension among men (left) and women (right) in multi-variable analyses in Eastern China and Northern Sweden 


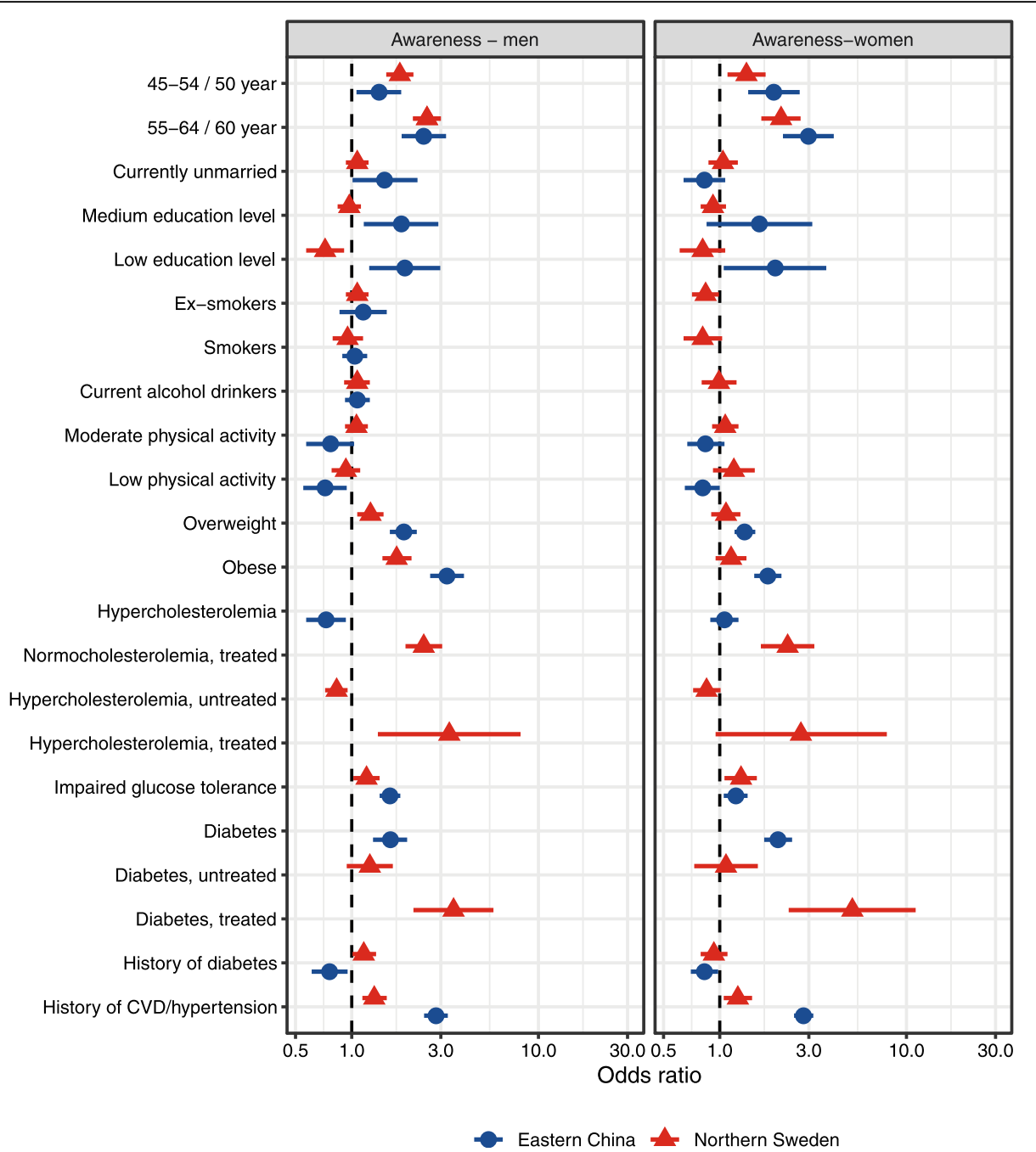

Fig. 2 The determinants of awareness of hypertensive men (left) and women (right) in multi-variable analyses in Eastern China and Northern Sweden 


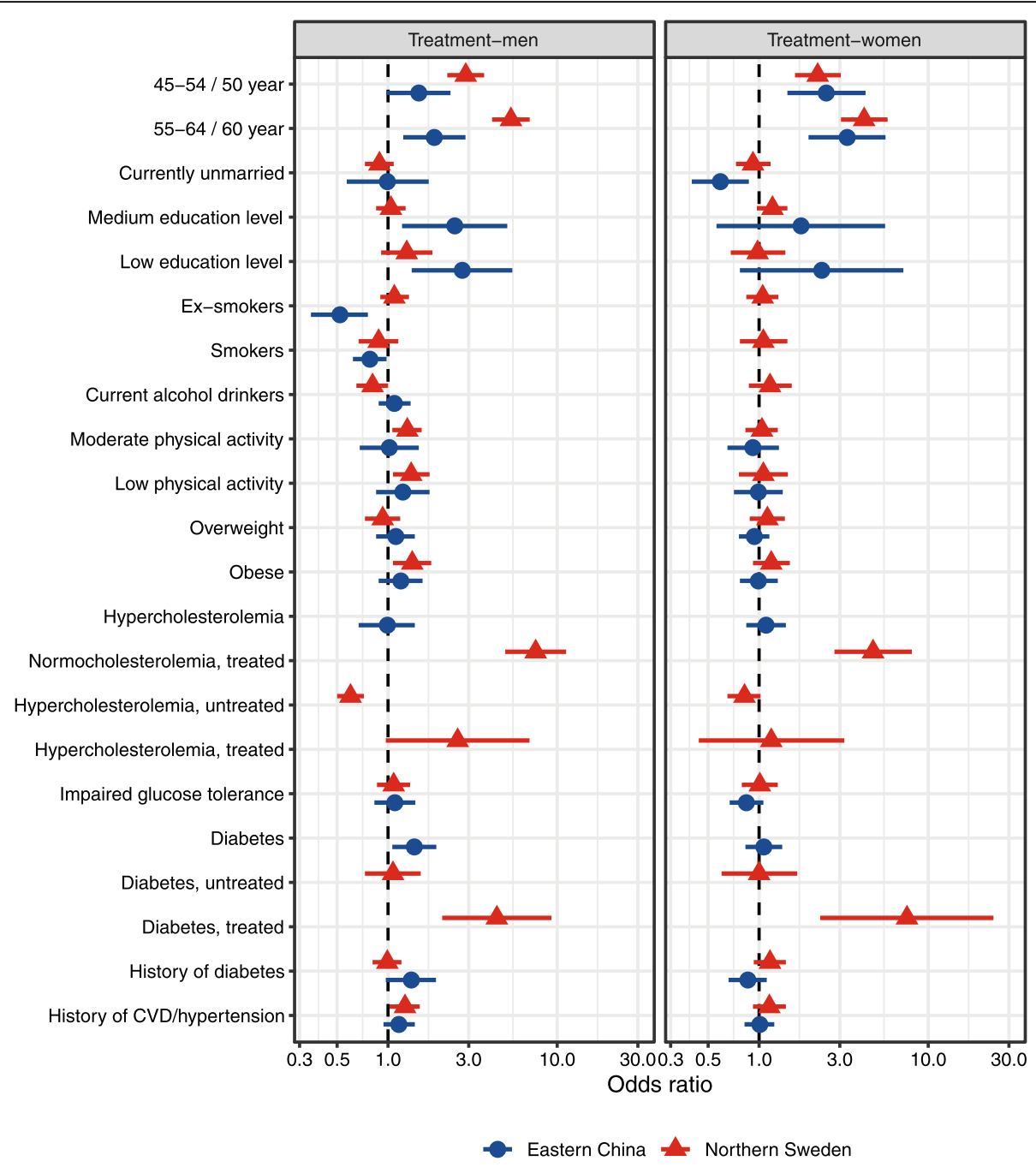

Fig. 3 The determinants of treatment of hypertension among men (left) and women (right) in multi-variable analyses in Eastern China and Northern Sweden 


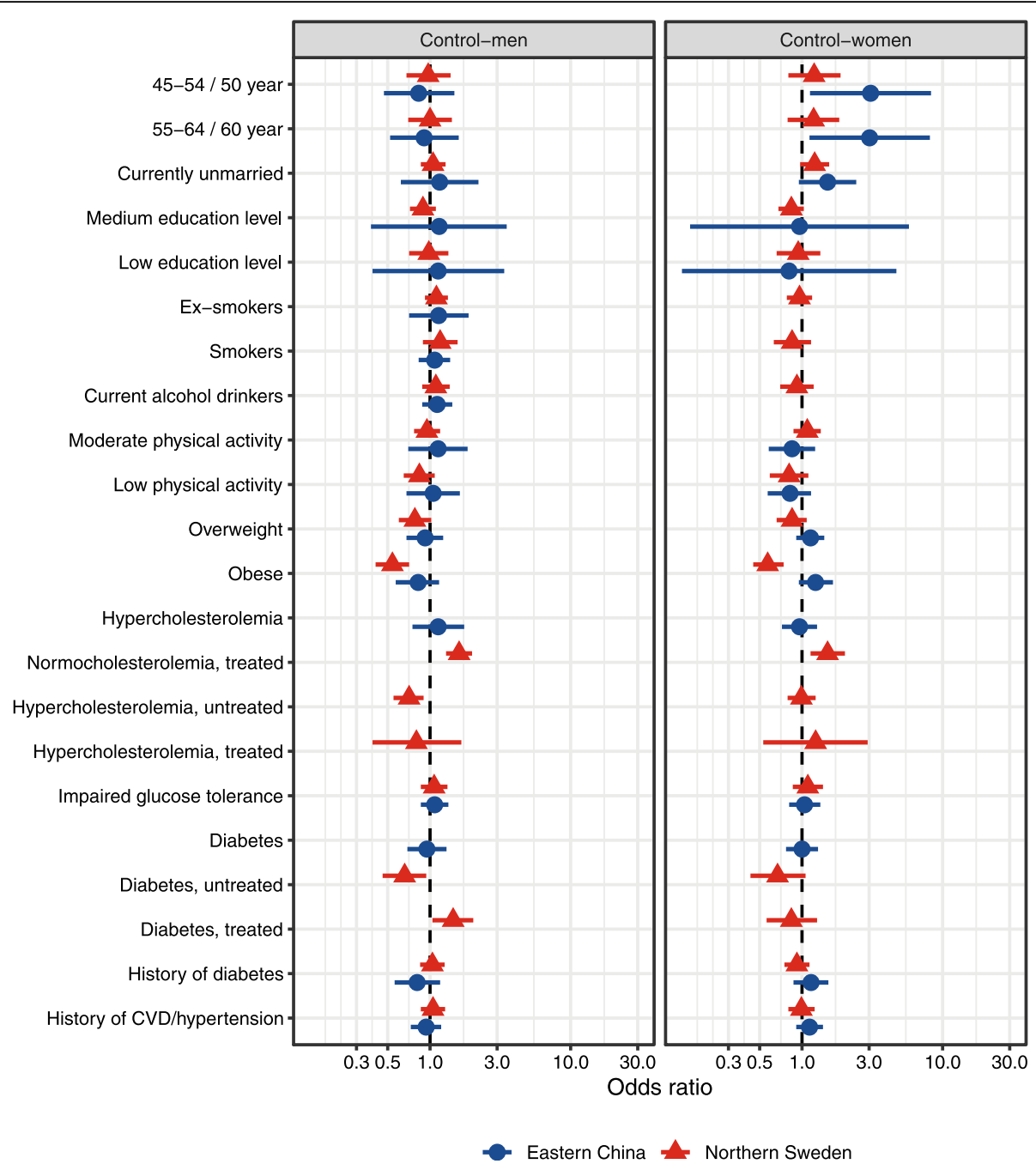

Fig. 4 The determinants of control for hypertension among men (left) and women (right) in multi-variable analyses in Eastern China and Northern Sweden 